УАK 577.29

\title{
CALCIUM SIGNALING IN TUMOR CELLS
}

Anna S. Zamay ${ }^{1,2}$, Olga S. Kolovskayad ${ }^{1,2}$, Nadegda M. Titova ${ }^{3}$,

Larisa L. Chesnokova ${ }^{2}$, Elena A. Maltceva², Tatiana N. Zamay ${ }^{2,3}$

${ }^{1}$ Krasnoyarsk Research Center, Siberian Branch, Russian Academy of Sciences, Akademgorogok, Krasnoyarsk;

${ }^{2}$ Voino-Yasenetskii State Medical University, Ministry of Health of the Russian Federation,

ul. Partizana Zheleznyaka 1, Krasnoyarsk,

${ }^{3}$ Siberian Federal University, Svobodnyi pr. 79, Krasnoyarsk.

The objective. The objective of this study was to investigate change in calcium maintenance of Ehrlich ascite adenocarcinoma cells in the course of tumor growth.

Materials and methods. Cell viability was determined by counting apoptotic and necrotic cells under the fluorescence microscope. Intracellular calcium concentration was determined with the fluorescent probe 2,5 mM Fura-2AM. Relative microviscosity of membranes was estimated by fluorescence method using Pyrene. The activity of Ca-ATPase was assessed by the amount of inorganic phosphate produced during ATP hydrolysis.

Results and discussions. We revealed that dynamics of Ehrlich ascite adenocarcinoma growth in our experiments was different from the commonly observed one. We noticed one peculiarity. The quantity of cells decreased on the day 12 after the tumor transplantation. This diminution was caused by mitotic activity lowering and by increase of apoptotic cell quantity the day before. Ehrlich ascite adenocarcinoma growth was accompanied by change in intracellular calcium maintenance which was independent of Ca-ATPase and cell membrane microviscosity.

Conclusions. Thus, our experiments have shown the change in calcium concentration. Apparently $\mathrm{Ca}^{2+}$ activated proliferation. However calcium maintenance was settled by ROS. Possibly ROS supression in tumour on the day 12 was able to put down proliferative processes stimulation.

Key words. Ehrlich ascite adenocarcinoma $\mathrm{Ca}^{2+}, \mathrm{Ca}$-ATPase, membrane microviscosity, apoptosis, necrosis.

The problem of a cell cycle regulation in normal and transformed cells is worked up today. It is clear that expression of numerous genes controlling the cell cycle activates in cancer cells [1]. Genome deviation was considered to be the main factor of tumour transformation [2]. Recent studies have revealed an important role of epigenetic modifications in transmutation to cancer cell [3]. Such events do not affect on the genes but lead to heritable modification of gene expression. Epigenetic events are linked with DNA methylation and chromatine inheritance $[4,5,6]$.

The reason reducing to this chemical modification is not clear today. It is assumed that gene expression depends on calcium maintenance in the cell nucleus. $\mathrm{Ca} 2^{+}$changes chromatine structure bonding with high affinity to DNA and calcium-binding nuclear proteins. An intracellular oscillatory calcium system produces a prerequisite for activation of gene expression $[7,8]$. The data on this cation content in cells at different stages of a cell cycle are ambiguous and sometimes contradictory $[9,10]$. The objective of this study was to investigate change in calcium maintenance of Ehrlich ascite adenocarcinoma cells in the course of tumor growth. We also tried to explore a possible reasons of these changes.

\section{Materials and methods}

Collecting ascite cells. All ascite cells were isolated from the abdominal cavity of ICR albino mice on the day 5-16 after transplantation of Ehrlich ascite adenocarcinoma. The number of the animals was 15-25 per day. 5 million cells were transplantated to a mouse at the experiment. Carefully treated cells were washed three times with Henks solution containing $(\mathrm{mM}): \mathrm{NaCl}-140$, $\mathrm{KCl}-5.4, \mathrm{CaCl}_{2}-1.3, \mathrm{MgSO}_{4}-1, \mathrm{KH}_{2} \mathrm{PO}_{4}-1$, 
$\mathrm{Na}_{2} \mathrm{HPO}_{4}-1, \mathrm{NaHCO}_{3}-1$, glucose -6 , HEPES - 10, pH 7.2. Cells were counted in the Goryaev chamber.

Apoptosis and necrosis measurement. Cell viability was determined by counting apoptotic and necrotic cells under the fluorescence microscope. Cells were incubated for $10 \mathrm{~min}$ at room temperature with fluoriscent dyes Hoechst 33342 (Sigma, 2 mg/ml) and Propidium iodide (Sigma, 1mg/ml) [11]. The percentage of living cells was calculated by counting cells with low level of fluorescence, apoptotic ones with higher level of blue, necrotic cells show red or both red and blue fluorescence.

Calcium measurement. Intracellular calcium concentration was determined in 1 million cells loaded (30 min. at $37^{\circ} \mathrm{C}$ ) with the fluorescent probe $2,5 \mathrm{mM}$ Fura-2AM (Serva) [12]. Cells were washed twice at Henks solution. $\left[\mathrm{Ca}^{2+}\right]_{\text {in }}$ was determined from the Fura-2AM fluorescence intensity using the formula: $\left[\mathrm{Ca}^{2+}\right]_{\text {in }}=\mathrm{Kd}$ (F-Fmin)/ (Fmax-F), where Kd is the dissociation constant of Fura-2 for $\mathrm{Ca}^{2+}\left(135 \mathrm{nM}, \mathrm{t}=25^{\circ} \mathrm{C}\right), \mathrm{F}$ is an intensity of a sample fluorescence, Fmin is the background fluorescence and Fmax is the maximal fluorescence obtained by equilibrating the $\left[\mathrm{Ca}^{2+}\right]_{\text {in }}$ and the extracellular $\mathrm{Ca}^{2+}$, using $6 \mathrm{mM}$ concentration of digitonin in $\mathrm{Ca}^{2+}$-containing medium Exitation wavelength was $340 \mathrm{~nm}$, emition wavelength was $510 \mathrm{~nm}$.

Membrane microviscosity measurement. Relative microviscosity of membranes was estimated by fluorescence method using Pyrene (Sigma) as a probe [13]. Evaluation is based on formation of excited pyrene eximers. Coefficient of pyrene eximerization is pyrene eximers intensity of fluorescence (emition wavelength was $470 \mathrm{~nm}$ ) divided by pyrene monomers intensity of fluorescence (emition wavelength was $395 \mathrm{~nm}$ ). This coefficient is inversal to membrane relative microviscosity. Relative microviscosity of lipid bilayer was measured at $334 \mathrm{~nm}$, protein/lipid contacts at $286 \mathrm{~nm}$. All measurements were performed in an Aminco Bowman Series 2 spectrofluorimeter (United States).

$\mathrm{Ca}$-ATPase activity measurement. The activity of $\mathrm{Ca}$ ATPase was assessed by the amount of inorganic phosphate produced during ATP hydrolysis by preparations of these enzymes as described in $[14,15]$. Enzyme preparations were obtained by homogenization of ascite cells in ten volumes of a medium containing $0.2 \mathrm{M}$ sucrose, $1 \mathrm{mM}$ EDTA, 0.09\% SDS, 30 mM Tris-HCl (pH 7.4).

The results were analyzed using the Origin 5.0 Program.

\section{Results and discussions}

We revealed that the dynamics of Ehrlich ascite adenocarcinoma growth (Fig. 1) in our experiments were different from the commonly observed one $[16,17]$. We noticed one peculiarity. The quantity of cells decreased on the day 12 after the tumor transplantation. Probably, this event reflected phenomena of interaction between an organism and the tumour that led to the multitude cell death. Such behaviour of the tumour growth curve was not typical, and therefore unexpected. Minimum on the growth curve pointed to the presence of two competitive mechanisms of tumour development regulation. One of them stimulated the rise and the other suppressed it and even contributed to apoptosis of ascite cells. It is naturally to suppose that the cell quantity decrease depends on mitotic activity repression and cell death stimulation in the cell population.

Mitotic activity was evaluated as a number of cell doubling during the day in the cell population in the course

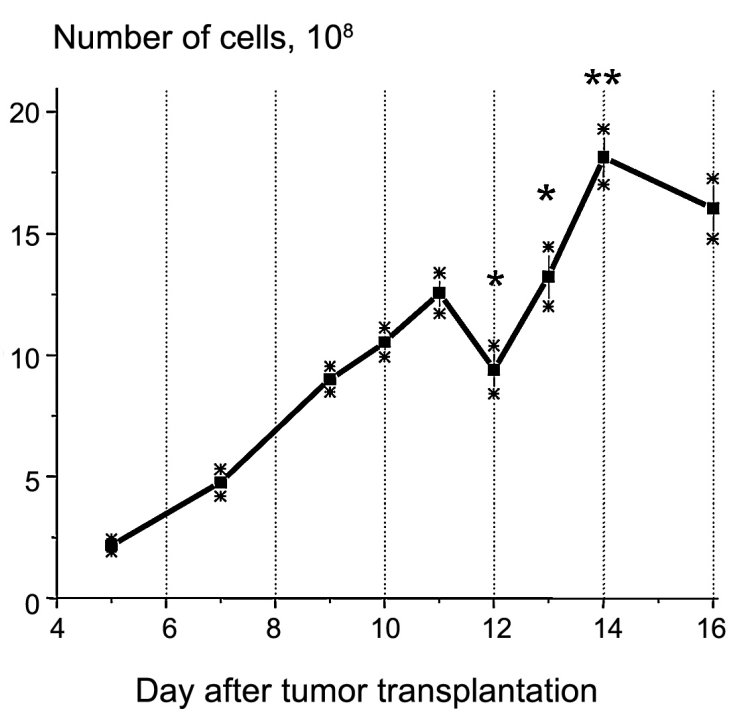

Fig. 1. The dynamics of Ehrlich ascite adenocarcinoma growth ${ }^{\star} P<0,05$; ${ }^{\star \star} P<0,01$. 


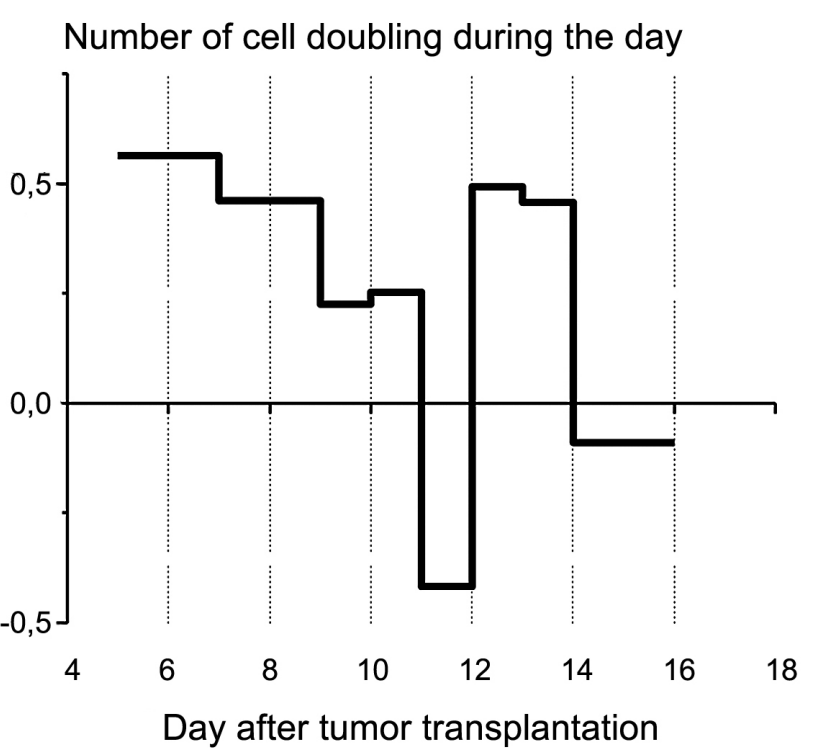

Fig. 2. Number of cell doubling during the day in the cell population in the course of tumor growth.

of tumor growth (Fig. 2). The maximum was revealed on the days 5 and 12, and the minimum on the days 11 and 14,15 . Thus the number of cell doubling reduction on the day 11 forestalled cell quantity diminution. On the day 12 the mitotic activity increased. This took place before the second wave of tumour growth on the day 13.

The cell number reduction can not be uniquely explained by the lowering of their mitotic activity. So we measured cell viability counting apoptotic and necrotic cells during the tumour development (Fig. 3). The investigations have shown that the number of necrotic cells was practically invariable. The number of apoptotic cells have been stable until the day 10 as well. But the level of apoptosis in the cell population sharply rised on the day 11. It coincided with the cell doubling reduction. Possibly these two factors resulted in the cell quantity decrease on the day 12.

Energy-supply of the vivid cells became better because of the reduced density at the expense of cells dying. It stimulated the new lifting of mitotic activity and hampered apoptosis until the terminal phase on the day 14. Then apoptosis started and the number of vivid cells decreased on the days 14-16.

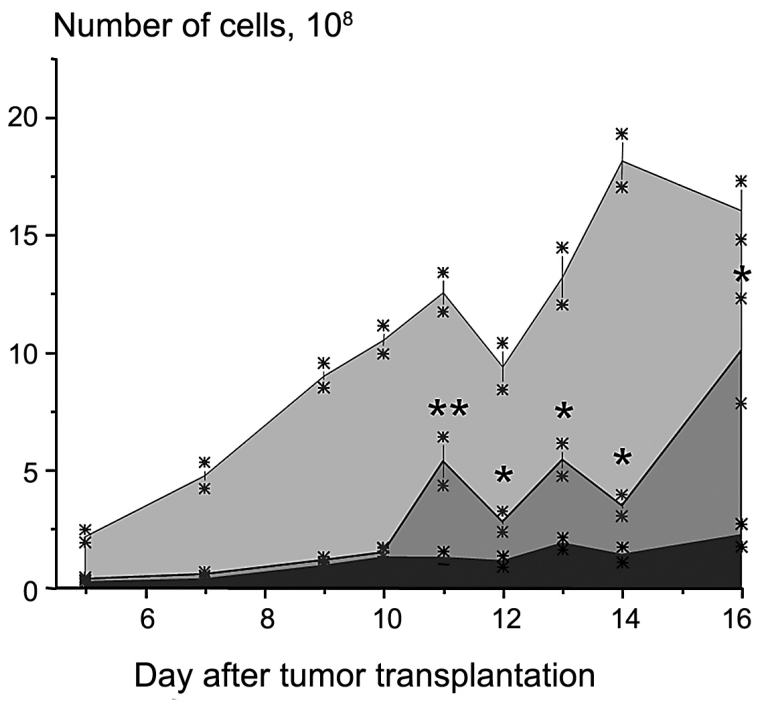

Fig. 3. Cell viability during the tumor development

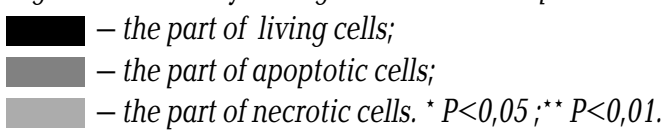

It is well known that $\mathrm{Ca}^{2+}$ regulates cell proliferation, differentiation and apoptosis [18]. It is established that the same signal molecules stimulate different systems of calcium-signaling in mature and nondifferentiated cells. It leads to achievement of various biological effects. In particular, norepinephrine acts to $\beta$-adrenoreceptors

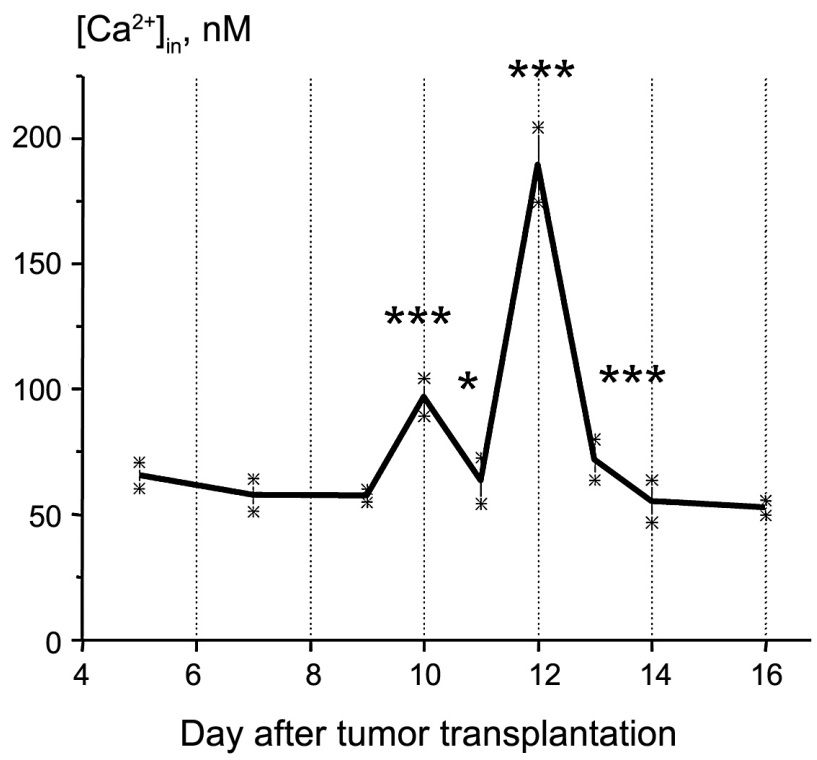

Fig. 4. Intracellular calcium concentration in the course of tumor growth ${ }^{\star} P<0,05 ;{ }^{\star \star \star} P<0,001$. 
Ca-ATPase aktivity,

mkM Pi/106 cells / $\mathrm{h}$ per $\mathrm{mg}$ protein

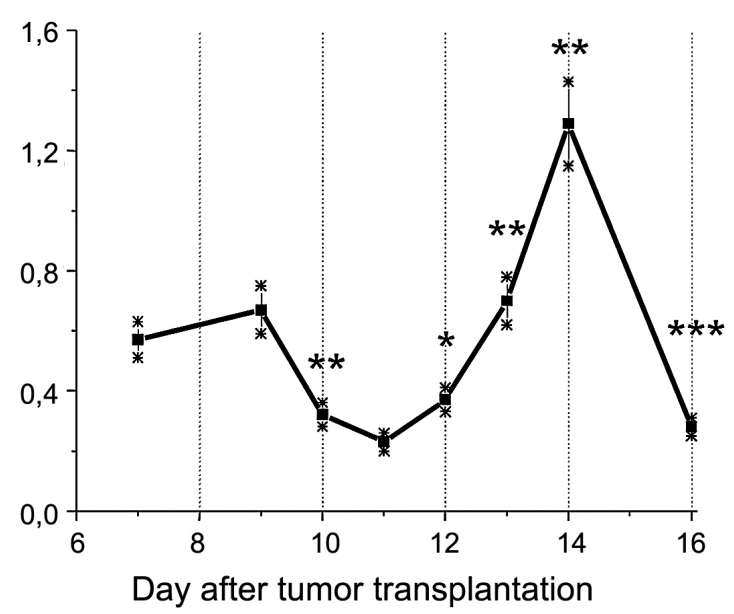

Fig. 5. Changes in the Ca-ATPase aktivity during the tumour development. ${ }^{\star} P<0,05 ;{ }^{\star \star}{ }^{\star} P<0,01 ;{ }^{* \star \star} P<0,001$

of preadipocites causing low-amplitude (by $200 \mathrm{nM}$ ) calcium maintenance increase and stimulates proliferation. Norepinephrine in mature adipocites acts to $\alpha_{1}$-adrenoreceptors causing high-amplitude (by $600 \mathrm{nM}$ ) calcium maintenance increase and evokes another biological effects [19]. Our experiments have shown different mitotic activity in the course of tumour growth. The objective of this study became the investigation of change in calcium maintenance which is able to stimulate proliferation of Ehrlich ascite adenocarcinoma cells.

We revealed that the concentration of intracellular calcium in the course of tumor growth significantly changed (Fig.4). It depended on the stage of the Ehrlich ascite adenocarcinoma growth and had two maximums on the day 10 and 12 .

Let us compare the change in calcium maintenance with the tumour growth dynamics. The increased calcium maintenance on the day 12 forestalled the rising of the ascite cells number on the day 13. Probably this fact is the evidence of calcium participation in cells proliferation. The $\mathrm{Ca}^{2+}$ content which activate tumour growth in our experiments was in line with calcium concentration stimulating preadipocites proliferation (about $200 \mathrm{nM}$ ) [19].

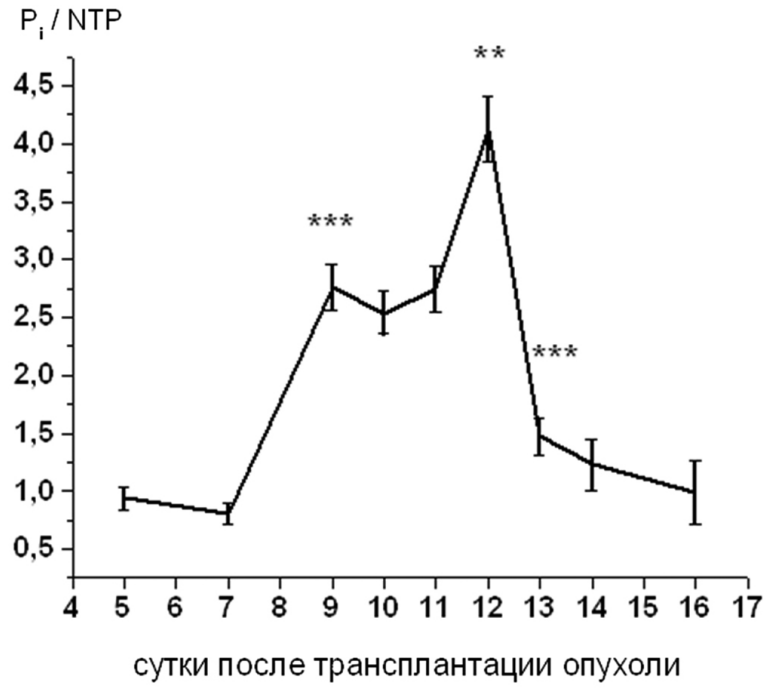

Fig. 6. Membrane fluidity in the course of tumor growth: 1- protein / lipid contacts; 2-lipid bilayer.

We measured the activity of Ca-ATPase to determine the factor causing changes in the content of $\mathrm{Ca}^{2+}$ in ascite cells at different stages of cell growth. We have found that the activity of this enzyme in the exponential growth phase changed slightly. It was considerably suppressed on the day 10-12, but increased sharply (three times) and then decreased again on the day 14 (Fig. 5). The curve of intracellular calcium maintanence looked like the curve of Ca-ATPase activity but the last was moved for two days. Thus, we have found no reliable correlation between the fluctuations in intracellular $\mathrm{Ca}^{2+}$ concentration and the Ca-ATPase activity. It is obviously that Ca-ATPase does not play the pivotal role in the regulation of this cation content in ascite cells during tumor growth.

Membrane viscosity is an integral parameter characterizing the structural and functional state of membranes. It regulates the activity of transport proteins and calcium, potassium and sodium homeostasis. An increase in membrane viscosity is usually accompanied by the increase in $\mathrm{Ca}^{2+}$ and $\mathrm{Na}^{+}$concentrations in cytoplasm because passive diffusion is enhanced and the activity of ion pumps is inhibited. We have determined this integral parameter to reveal the fluctuation causing 


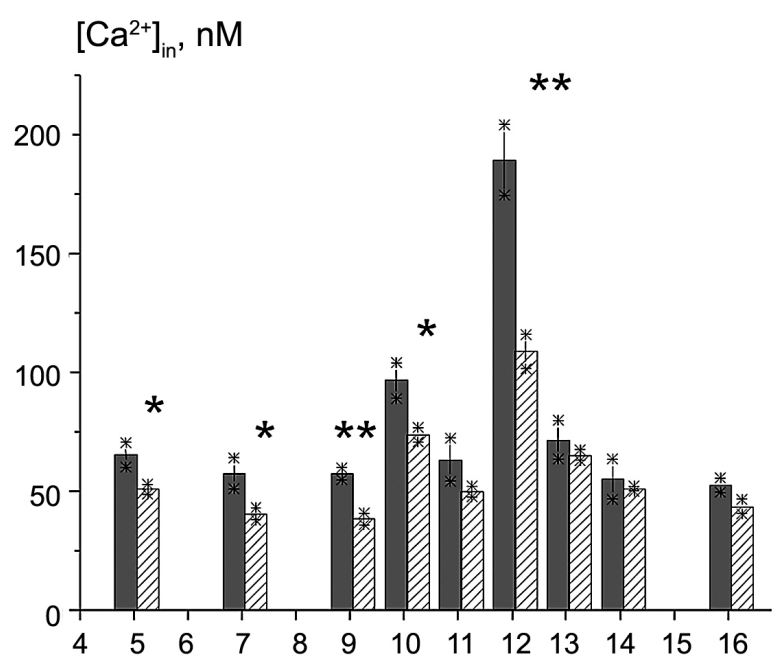

Day after tumor transplantation

Fig 7. Change in calcium concentration in the course of tumor growth in the absence of $R O S$

$-[\mathrm{Ca} 2+]$ in

$\mathbb{Z Z}-[\mathrm{Ca} 2+]$ in in the absence of $R O S$ (after incubation with $10 \mathrm{mM}$ N-acetyl-L-cysteine).

factor in the content of intracellular calcium during the tumor growth. It appeared that microviscosity of ascite cell membranes changed insignificantly during the tumor growth (Fig. 6). It applied to the lipid bilayer and to the zone of lipid-protein contact. Hence, the changes in membrane viscosity had no correlation with the changes in concentration of intracellular $\mathrm{Ca}^{2+}$ in ascite cells in the course of tumor growth. However, this cation can regulate the aggregation state of membranes. But we have noticed that the membrane relative microviscosity of ascite adenocarcinoma cells was much bigger than membrane relative microviscosity of erythrocytes and lymfocytes.

It is well known fact that an effect of the biologically active agents is mediates by (ROS) [20]. ROS suppression brakes cell division and differentiation. ROS quantity often increase under the influence of the agonists before the growth of calcium maintenance. So biological effect could be possibly determined by ROS. We determined calcium concentration in ascite cells after their incubation with $\mathrm{N}$ acetil-L-cysteine, which neutralizes the reactive oxygen species, to ascertain the role of ROS $[21,22]$.
We revealed that calcium concentration in ascite cells after the ROS suppression depended on stage of tumour growth (Fig. 7). The lowest $\mathrm{Ca}^{2+}$ concentration, depended on ROS to a lesser extent and vice versa. The largest calcium maintenance dependence from ROS was on the day 12 .

Thus we have obtained the dynamics of the tumour growth with the depression on the day 12 in two experiments in which 3 or 5 millions cells were inoculated to a mouse (Fig. 1). We have explored the reason of such slump and have demonstrated the mitotic activity reduction and the magnification of the apoptotic cell quantity.

Obviously the day 11 became critical for Ehrlich ascite adenocarcinoma. Probably the mitotic activity reduction and the magnification of the apoptotic cell quantity were provoked by hypoxia and a lack of nutrients which are necessary for active vital functions. Probably this happened because of cell density increase during the intensive growth of the tumour. Hypoxia can cause reduction of ATP maintenance in the cells and tumour growth supression [23]. It is remarkable, that some protooncogenes (Bcl-2 и $\mathrm{Bcl}-\mathrm{Xl}$ ) possess protective mechanisms which let tumour cells to survive [24].

The high mitotic activity on the day 5 and the rapid tumour growth caused the cell density magnification and the lack of energetic resources. It was followed by the decrease of the tumour growth rate. This lowering and even the stop of the adenocarcinoma growth was accompaned by ascite solution accumulation, energy-supply improvment and cancer cells compactness reduction. The new wave of proliferating started and the second time cell mass augmentation began. However this stimulation was a short-term. The terminal phase have come soon. The mitotic activity depressed probably because of the nutrisity lack.

The growth of Ehrlich ascite adenocarcinoma was accompanied by the change of the calcium maintenance. Probably the increase of the $\mathrm{Ca}^{2+}$ concentration was contributed by the tumour growth stimulation.

ROS directly participate in realization of physiological response to hormones and cytokines. Cellular reac- 
tion determines not only the kind of regulator but he ROS level as well [25]. Also the ROS formation in different cell types is the fast postreceptor process. ROS generation precedes all occurrence in intracellular informational succession of events first of all calcium maintenance [26]. Besides ROS can simulate action of agonists [27], they regulate enzyme activity $[28,29]$. We show that cellular reply to a regulator and the level of intracellular calcium depended on ROS presence. The largest $\mathrm{Ca}^{2+}$ concentration, depended on ROS to a greater extent. It is imposobel to fix the reason of such interdependency without investigation of physicochemical propeties of membranes. We assume that the cause is the differences in membrane characteristics in the different stages of tumour growth with the unequal mitotic activity. Thus, our experiments have shown the change in calcium concentration. Apparently $\mathrm{Ca}^{2+}$ activated proliferation. However calcium maintenance was settled by ROS. Possibly ROS supression in tumour on the day 12 was able to put down proliferative processes stimulation.

\section{Acknowledgments}

This work was supported by the Russian Science Foundation (project no. 14-15-00805).

\section{References}

1. Knowles M.A. Oncogenes. In: Knowles M., P. Selby ed. Introduction to the Cellular and Molecular Biology of Cancer, Oxford, University Press, 2005: 117-134.

2. Irminger-Finger I., 3 rd Geneva aging wockshop 2002: cancer, apoptosis and aging. Biochim. Biophys.Acta. 2003; 1653:41-45.

3. Nair S.S., Kumar R. Chromatin remodeling in cancer: a gateway to regulate gene transcription. Mol. Oncol. 2012; 6(6):611-619.

4. Vanyushin B.F. Enzymatic DNA Methylation Is an Epigenetic Control for Genetic Functions of the Cell. Biochemistry. 2005; 70:598-611.

5. Szyf M. DNA Methylation and Demethylation as Targets for Anticancer Therapy. Biochemistry. 2005; 70:651-669.
6. Cheng C., Jones P.A. Epigenetic events in cancer. In: Knowles M., P. Selby ed. Introduction to the Cellular and Molecular Biology of Cancer, Oxford, University Press, 2005:78-94.

7. Hardingham G.E., Arnold F.J., Bading H. Nuclear calcium signaling controls CREB-mediated gene expression triggered by synaptic activity. Nat. Neurosci. 2001; 4:261-267.

8. Li J., Khodus G.R., Kruusmägi M., Kamali-Zare P., X.-L.Liu, Eklöf A.C., Zelenin S., Brismar H., Aperia A. Ouabain protects against adverse developmental programming of the kidney. Nature Communications. 2010; 42. doi:10.1038/ncomms1043.

9. T. Afroze, M. Husain, C-Myb-binding Sites Mediate G1/S-associated Repression of the Plasma Membrane Ca2 +-ATPase-1 Promoter, J. Biol. Chem. 275 (2001) 9062-9069.

10. Monteith G.R., Davis F.M., Roberts-Thompson S.J. Calcium Channels and Pumps in Cancer: Changes and Consequences. J. Biol. Chem. 2012; 287(38): 31666-31673.

11. Izumov D.S., Avetisyan A.V., Pletjushkina O.Yu. "Wages of Fear": transient threefold decrease in intracellular ATP level imposes apoptosis. Biochim. Biophys.Acta. 2004; 1658:141-147.

12. Grinkievicz Y., Poenie M., Tsien R.I. A new generation of $\mathrm{Ca}^{2+}$ indicators with greatly improved fluorescence properties. J. Biol. Chem. 1985; 260:340-345.

13. Bordyushkov Y.N., Goroshinskaya I.A., Frantsiyants E.M. Structural- functional changes in lymphocyte and erythrocyte membranes under the influense of alternating magnetic field. Vopr. Med. Khim. (Biomedical Chemistry). 2000; 1:72-80.

14. Boldirev A.A. Transportnye adenozintrifosfatazy (Transport Adenosine Triphosphatases), Moscow: Mosk. Gos. Univ.; 1977. (In Russian)

15. Rathbun W.B., Betlach M.V. Estimation of enzimatically produced orthophosphate in the presence of cystein and adenosine triphosphate. Analyt. Biochem. 1969; 28:436-445. 
16. Varfolomeev S.D., Gurevich K.G. Biokinetika (Biokinetics). Moscow: Fair; 1999. (In Russian)

17. Emmanuel N.M. Kinetika eksperimental'nykh opukholevykh protsessov (The Kinetics of Experimental Tumor Growth). Moscow: Nauka; 1977. (In Russian)

18. Bhosale G., Sharpe J.A., Sundier S.Y., Duchen M.R. Calcium signaling as a mediator of cell energy demand and a trigger to cell death. Ann. N.Y. Acad. Sci. 2015; 1350:107-116.

19. Dolgacheva L.P., Abzhalelov B.B., Zhang S.J., Zinchenko V.P., Bronnikov G.E. Norepinephrine induces slow calcium signalling in murine brown preadipocytes through the $b$-adrenoceptor/cAMP/protein kinase A pathway. Cell Signal. 2003; 15:209-216.

20. Navarro-Yepes J., Burns M., Anandhan A., Khalimonchuk O., del Razo L.M., Quintanilla-Vega B., Pappa A., Panayiotidis M.I., Franco R. Oxidative stress, redox signaling, and autophagy: cell death versus survival. Antioxid Redox Signal. 2014; 21(1):66-85.

21. O'Loghlen A., Perez-Morgado M.I., Salinas M., Martin M.E., N-acetyl-cystein abolishes hydrogen peroxide-induced modification of eucariotic initiation factor $4 \mathrm{~F}$ activity via distinct signaling pathways. Cellular Signalling. 2006; 18:21-31.

22. Screck R., Rieber R., Baeuerle P.A. Reactive oxygen intermediates as apparently widely used messengers in the activation of the NF-kappaB transcription factor and HIV-1. EMBO J. 1991; 10:2247-2258.

23. Krtolica A., Ludlow J.W. Hypoxia arrests ovarian carcinoma cell cycle progression but invasion is unaffected. Cancer Res. 1996; 56:1168-1173.

24. Shimizu S., Eguchi Y., Kamiike W. Induction of apoptosis as well as necrosis by hypoxia and predominant prevention of apoptosis by Bcl-2 and Bcl-XL. Cancer Res. 1996; 56:2161-2171.

25. Burlando B., Viarengo A. Ca2+ is mobilized by hydroxyl radical but not by superoxide in RTH-149 cells: The oxidative switching-on of $\mathrm{Ca} 2+$ signaling. Cell calcium. 2005; 38:507-513.
26. Massart C., Hoste C., Virion A., Ruf J., Dumont J.E., Van Sande J. Cell biology of $\mathrm{H} 2 \mathrm{O} 2$ generation in the thyroid: Investigation of the control of dual oxidases (DUOX) activity in intact ex vivo thyroid tissue and cell lines. Molecular and Cellular Endocrinology. 2011; 343: $32-44$.

27. Vázquez-Meza H., de Piña M. Z., Pardo J.P., RiverosRosas H., Villalobos-Molina R., Piña E. Non-steroidal anti-inflammatory drugs activate NADPH oxidase in adipocytes and raise the $\mathrm{H} 2 \mathrm{O} 2$ pool to prevent cAMPstimulated protein kinase a activation and inhibit lipolysis. BMC Biochem. 2013; 14:13.

28. Berndt C., Lillig C.H., Flohé L. Redox regulation by glutathione needs enzymes. Front. Pharmacol. 2014. http://dx.doi.org/10.3389/fphar.2014.00168.

29. Lennicke C., Rahn J., Lichtenfels R., Wessjohann L.A., Seliger B. Hydrogen peroxide - production, fate and role in redox signaling of tumor cells. Cell Communication and Signaling. 2015; 13:39.

\section{Authors}

Zamay Anna Sergeevna - Dokt. Biol. Sc., Laboratory For Biomolecular and Medical Technologies, Krasnoyarsk State Medical University named after Prof. V. F.VoinoYasenetski, Ministry of Health of the Russian Federation.

Address: 1, Partizana Zheleznyaka St., Krasnoyarsk, 660022; Phone: +7(963) 9596351, e-mail: annazamay@yandex.ru

Kolovskaya Olga Sergeevna, Kand. Biol. Sc., Laboratory For Biomolecular and Medical Technologies, Krasnoyarsk State Medical University named after Prof. V. F. Voino-Yasenetski, Ministry of Health of the Russian Federation.

Address: 1, Partizana Zheleznyaka St, Krasnoyarsk, 660022; Phone:+7(963)9596351, e-mail: olga.kolovskaya@gmail.com

Titova Nadegda Mitrofanovna, Kand. Biol. Sc., Siberian Federal University.

Address: Svobodnyi pr. 79, Krasnoyarsk, 660041 Russia, Phone: +7 (391) 228-08-76; E-mail: tinami6@mail.ru

Chesnokova Larisa Leonidovna, Kand. Med. Sc., Krasnoyarsk State Medical University named after Prof. V.F.Voino-Yasenetski, Ministry of Health of the Russian Federation.

Address: 1, Partizana Zheleznyaka St., Krasnoyarsk, 660022; Phone: +7 (913) 8329857

Maltceva Elena Alexandrovna, Kand. Med. Sc., Krasnoyarsk State Medical University named after Prof. V. F. Voino-Yasenetski, Ministry of Health of the Russian Federation.

Address: 1, Partizana Zheleznyaka St., Krasnoyarsk, 660022; Phone: +7 (391) 2283640

Zamay Tatiana Nikolaevna - Dr. Biol. Sc., Laboratory For Biomolecular and Medical Technologies, Krasnoyarsk State Medical University named after Prof. V. F. Voino-Yasenetski, Ministry of Health of the Russian Federation.

Address: 1, Partizana Zheleznyaka St., Krasnoyarsk, 660022; Phone: +7(963) 9596313, e-mail: tzamay@yandex.ru 